\title{
Crítica e autocrítica
}

\author{
EDUARDO PORTELLA*
}

$\mathrm{C}$

ONFESSO que, pessoalmente, é a primeira vez na minha vida que falo alguma coisa sobre mim mesmo. Nunca fui analisado e nunca fui chegado a certos tipos de dissertação pessoal. Mas, achei a idéia perfeita - na Europa acontece muito esse tipo de iniciativa - e aqui estou tentando dar conta do meu trabalho.

Lembro-me de que, uma vez, na minha vida, vivi um momento muito responsável, muito tenso, muito difícil. Nesse momento fui ao Congresso Nacional e fiz um discurso. Desse discurso tiraram pelo menos uma frase que se incorporou ao folclore nacional. Mas há outra que só o jornalista Helio Fernandes retirou, e foi aquela em que eu dizia: "Eu não sou tema de mim mesmo", na medida em que as pessoas foram fazendo perguntas de natureza muito pessoal.

Mas a convite de Antonio Carlos Secchin e na perspectiva de iniciar uma outra vereda nesse conjunto de iniciativas do Presidente Ivan Junqueira, eu entendi que devia aceitar e me expor, de alguma maneira, à visitação pública.

Não sou, primeiramente, senhor do meu destino, já que esta expressão ficou famosa por uma novela recente. Sou obra do acaso. Na verdade, nunca planejei nada e fui surpreendido pela vida.

Procurei recolher essas surpresas da vida com alguma satisfação pessoal, às vezes até com alguma imprudência. Desde pequeno, na Bahia, a família gostava de dizer: esse menino é muito crítico. A palavra não tinha a tecnicidade que veio a ter posteriormente. Era simplesmente alguém que observava e, vez ou outra, ou emitia uma opinião ou colocava um apelido em alguém. Tática muito freqüente na minha terra.

Tenho uma formação diversificada. Sou bacharel em Ciências Jurídicas e Sociais e em Filosofia e Letras, sobretudo em Madri. As minhas cidades são Recife, Madri, Paris e Rio de Janeiro. Com relação ao Rio, costumo dizer que sou, às vezes, mais carioca do que os cariocas, porque em mim a condição de carioca não é um acidente biográfico. É uma opção livre. É uma escolha do exercício pleno da minha soberania. Por isso eu me sinto profundamente carioca.

Comecei a me movimentar nessa área quando as Faculdades de Letras apenas nasciam. E porque nasciam, conservavam tradições passadas. Os baianos estudavam Direito no Recife e os pernambucanos, Medicina na Bahia. Era uma velha tradição, que só foi progressivamente desfeita com o aparecimento individualizado de diferentes faculdades: de Ciências Sociais, de Letras, de Filosofia etc.

* Depoimento dado durante o III Ciclo de Conferências "Caminhos do Crítico", na Academia Brasileira de Letras, em 31 de maio de 2005. 
A Europa, portanto, dentro desse quadro, aparecia como uma espécie de porto seguro para quem tinha veleidades literárias. Primeiro foi Madri - e eu tive o privilégio de ser aluno de Menéndez Pidal, Damaso Alonso e Carlos Bousoño, na área de Letras, e de Ortega y Gasset, Xavier Zubiri e Julián Marías na área de Filosofia. Em Paris, fui aluno de Marcel Bataillon, outro grande filólogo. E assistia, às vezes curiosamente, às vezes atrevidamente, e às vezes timidamente, a um grupo que se reunia no Café de Flore, em torno de Jean-Paul Sartre. Cheguei a ter uma relação pessoal com Sartre, tanto que tive a honra de trazê-lo ao Brasil. Fiz um congresso de Crítica e História Literária na Universidade Federal de Pernambuco e o reitor, a pedido meu, me autorizou convidá-lo. Sartre exigiu que fosse acompanhado de Simone de Beauvoir, e ela também veio.

Quando chegou ao Recife - eu tinha uns vinte e tantos anos - fui fazendo logo aquela pergunta convencional e batida que todo mundo faz: "O senhor pretende escrever sobre o Brasil?” Ele tinha escrito um livro sobre Cuba, era recente, que sairia aqui pela Editora do Autor, de Fernando Sabino. Ele me disse: "Se eu conseguir entender o Brasil, escreverei". Quinze dias depois, voltei a uma meia pergunta: "E então?" Ele: "Acho que vou escrever, sim".

Fiquei muito tranqüilo e muito satisfeito. Mais quinze dias depois ele me disse: "Não vou escrever nada porque não estou entendendo nada". Achei que ele tinha toda razão. Mais uma vez a lucidez dele se manifestou. Ele fez uma coisa que talvez até nós próprios fazemos todos os dias: fez um esforço tenaz, e provavelmente fracassado, de entender o Brasil.

Em Madri tive como companheiro - um companheiro que me marcou muito - o professor Rafael Gutiérrez, que veio a ser catedrático na Universidade de Bonn, a mesma Universidade de que foi reitor Ernest Robert Curtius, e outras grandes figuras. Por intermédio dele eu me introduzi na filosofia de Heidegger, que estava muito em voga na Espanha da época, assim com Gadamer. Ele traduziu para o espanhol a Carta sobre o humanismo de Heidegger, que continua sendo um livro fundamental, em que Heidegger aconselha Sartre a ler um pouco mais sobre o marxismo, conselho este que teve suas conseqüências. De maneira que nessa Madri dos anos de 1950 eu tive algumas grandes convivências, sejam formais, acadêmicas, ou informais, ou seja, convivências que pertencem à vida literária e que não devem entrar neste inventário mais ou menos seletivo.

Conheci um grande poeta espanhol que me marcou muito, um basco chamado Blas de Otero. Impressionou-me porque era um poeta muito enraizado e, simultaneamente, universal. Por causa dessas circunstâncias, como disse, as minhas cidades são Recife, Madri, Rio, Paris.

Comecei pela crítica influenciado, estimulado e instado, algumas vezes, por Gilberto Freyre, Mauro Mota, Celso Cunha, Afrânio Coutinho, Antônio Houaiss e Alceu Amoroso Lima. Com Antônio Houaiss tive uma feliz coincidência: dediquei a ele o meu primeiro livro e ele me dedicou o último livro dele. De maneira que é uma amizade que conseguiu atravessar algumas décadas. Alceu 
era, para mim, a figura do mestre, a personalização do crítico. O crítico isento, generoso, não o juiz investido artificialmente de uma autoridade superior.

Aliás, eu deixei a crítica quando percebi que era um magistério sem concurso, sem autorizações maiores, que emitia, desde um plano superior, que é muito difícil de se saber por que superior, juízos críticos sobre as obras recémchegadas. Não concordo com essa vontade de ser juiz, não tenho vocação para isso, não gosto disso. E acredito que o juiz está investido de uma superioridade crítica que eu não estou certo de que ele disponha. Pelo menos os casos brasileiros, freqüentes na televisão de nossos dias, indicam que essa investidura pode e deve ser contestada.

Comecei pela crítica e tive queridos amigos. Pensei em praticar a crítica literária em três níveis, em três dimensões. Eu os chamava de "dimensões" na época e os meus livros foram publicados com esse título. No fundo, tinham uma influência remota das Situations de Sartre. Sartre sempre foi a minha grande paixão. Via nele o intelectual público, não exatamente o intelectual partidarista, não se trata disso, mas um intelectual inscrito radicalmente no espaço público. Isso era Sartre para mim. Com os erros, com as curvas fechadas próprias do século XX, mas de qualquer maneira um intelectual extremamente representativo.

Essa crítica em três dimensões tentava dizer a razão interna do texto literário. Era nisso que ela se distinguia da crítica impressionista. Esta estabelecia imediatamente o que chamavam julgamento com o primeiro contato, de natureza subjetiva, ou seja, estabeleciam contatos empáticos e imediatamente promoviam avaliações e condenações definitivas. Aí eu me afastei progressivamente desse tipo de comportamento.

$\mathrm{O}$ meu trabalho crítico, o meu percurso, talvez tenha dois momentos. $\mathrm{O}$ primeiro tem como base de sustentação a Estilística. Então, na primeira dimensão, é o contato empático, intuitivo, um contato inevitavelmente impressionista. O segundo é um momento já de operação instrumental, de tentativa de deslindamento técnico da obra. O terceiro - não gosto da palavra julgamento, mas talvez da palavra avaliação - é o momento de uma colocação diante da obra: sim ou não, mais isso de positivo, aquele outro de talvez questionável, e assim por diante.

Então eu registraria provavelmente esses dois momentos: o de base de sustentação estilística, que trouxe pelo menos uma maneira de olhar, voltado evidentemente para a estrutura do texto literário. No segundo momento do meu trajeto, procurei uma base de sustentação hermenêutica, uma leitura ontológica do texto. A razão de ser do texto. A razão de ser da linguagem. Não apenas a linguagem dada, mas a linguagem também silenciada.

Foi nessa perspectiva que eu me opus, sem nenhum parti pris, evitando qualquer tendência comprometedora, que resisti ao Estruturalismo. Em plena voga estruturalista publiquei dois livros: A teoria da comunicação literária e Fundamento da investigação literária. Ambos, publicados em 1970, iam na linha 


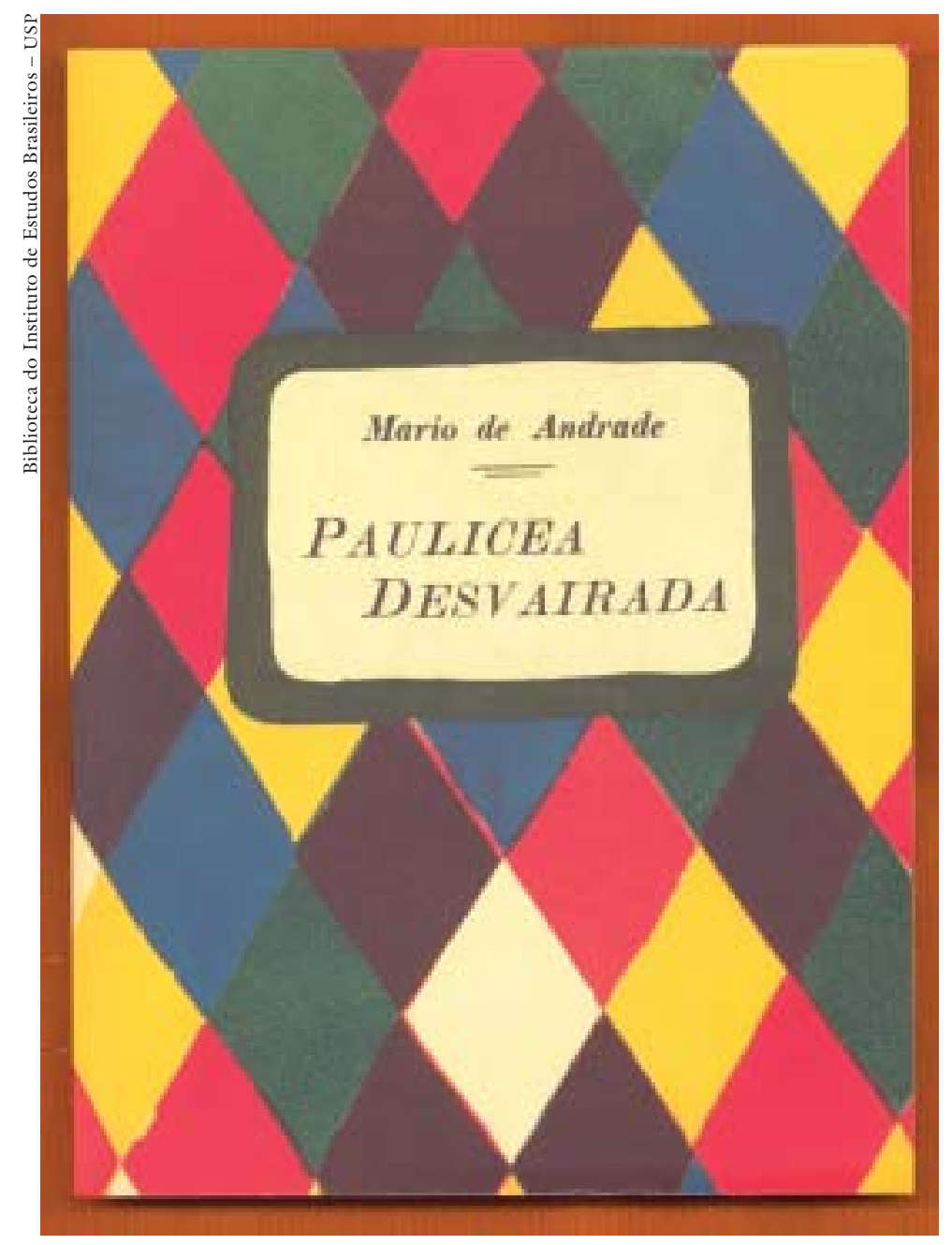

Capa da $l^{\underline{a}}$ edição de Paulicea desvairada

oposta do Estruturalismo. Eu partia do princípio de que o Estruturalismo não era capaz de dar conta de outras dimensões da linguagem literária, aquelas dimensões escondidas, silenciadas. O Estruturalismo não dispunha de meios para ler o silêncio. Eu queria que houvesse uma crítica capaz de ler o silêncio. Mas o silêncio, na verdade, é o mais dizer.'É tudo aquilo que se diz naquilo que se cala.

Então, na verdade, o crítico que pretenda interpretar, ou se aproximar, ou estabelecer uma espécie de co-naturalidade com a obra literária, precisa ter também esse espaço de co-habitação onde ele se junta ao fazer poético, sem o que ele ficará emitindo sentenças provavelmente estranhas ou distantes do texto.

Entre uma e outra atividade, ou seja, a crítica militante, semanal, no jornal, e a leitura hermenêutica na cátedra universitária, fui elaborando um esforço de recusa do Estruturalismo. Tinha uma margem de risco muito grande porque a época era fanaticamente estruturalista. Mas, digo não-tendencioso porque na nossa revista Tempo Brasileiro publicamos um número monográfico volumoso do Estruturalismo, do qual saíram cinco edições de três mil exemplares cada. É 


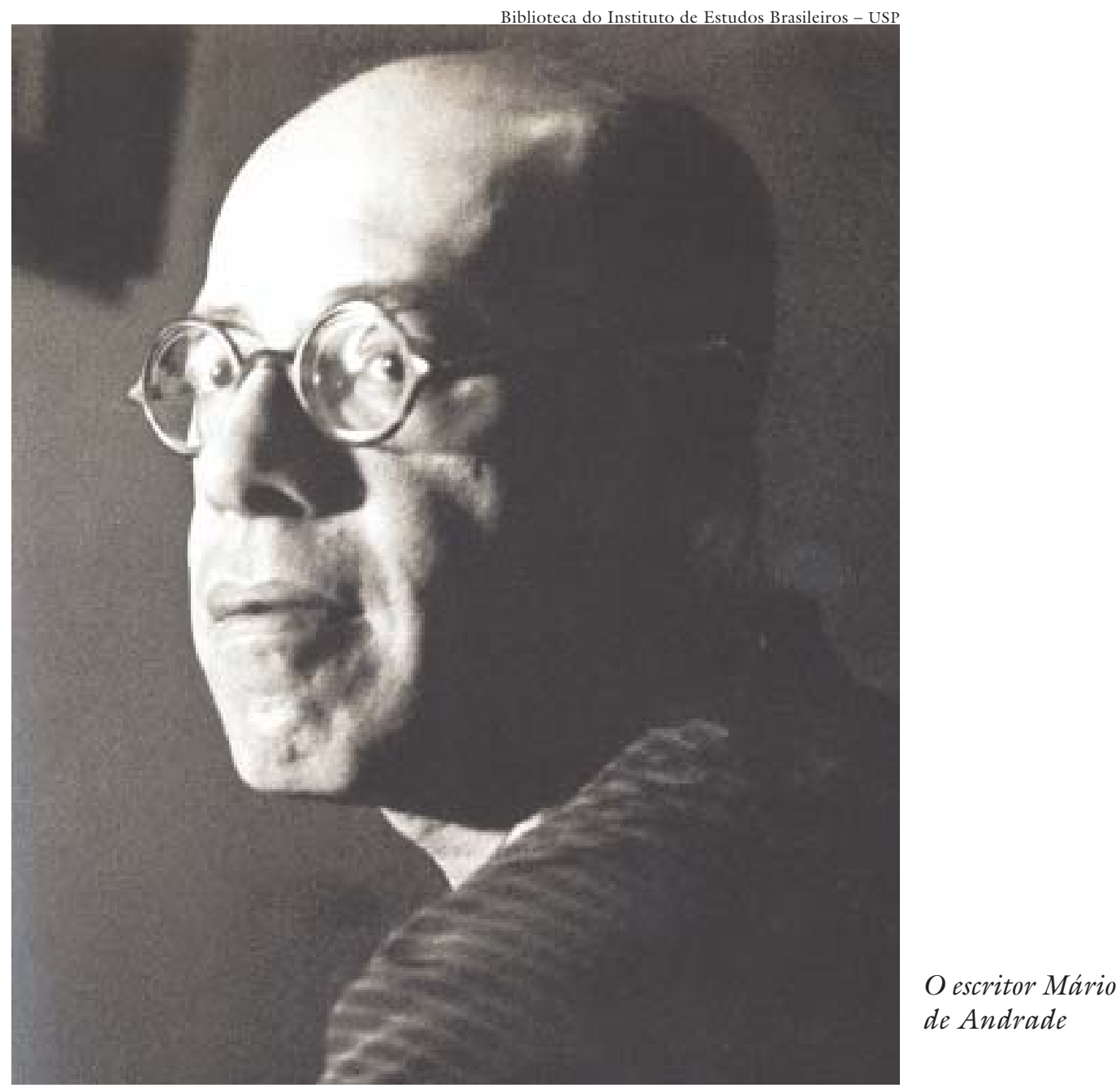

um fenômeno raro em vendagem editorial de uma revista técnica conseguir atingir cinco edições de três mil exemplares cada. E nós também lançamos, pioneiramente, no Brasil, os dois volumes da Antropologia estrutural de Lévi-Strauss, assim como um outro livro de um texto que ele me mandou pessoalmente, com palavras escritas do próprio punho, chamado Mito e linguagem social. De maneira que era uma separação com relação ao Estruturalismo, mas que não consistia em vedar o seu aparecimento. Significava, sim, pô-lo em questão, deixá-lo visível para podermos dialogar criticamente com ele.

Assim, fomos traçando, ou percorrendo um caminho, entre perdas e ganhos, por entre a Modernidade, o Modernismo e a contra-Modernidade. A Modernidade é aquele período que vem mesmo antes de 1922, e que está dentro de 1922, em alguns momentos, e que prossegue para além dele. Há, portanto, uma espécie de experiência moderna no poeta da cidade, como o foi precursoramente Mário de Andrade na sua Paulicéia desvairada, em perceber que tínhamos simultaneamente um espaço acolhedor, que era a cidade, e um monstro 
que começava a crescer. Esse momento que seria de modernidade alguns poetas do Modernismo o praticaram e outros poetas do Modernismo fizeram uma poesia saudosista, retrógrada e extremamente fundamentalista, quando se voltava para um Brasil profundo e fazia o grande elogio do Brasil profundo, como se o Brasil tivesse a obrigação de recusar a modernidade e todo um processo de urbanização que seria inevitável.

Em função disso eu tenho, com relação ao Modernismo, uma postura muito ambígua. Se, de um lado, sou capaz de aplaudir certas construções modernistas, de outro, também sou capaz de não perdoar certas incursões no Brasil profundo a título de novidade.

Essa Modernidade, se tentarmos fazer uma espécie de retrospectiva bem sintética dela, se resume em algumas perdas. A primeira dessas perdas da Modernidade é a perda do Paraíso. E foi John Milton que nos trouxe a palavra poética dessa primeira grande perda. Em seguida tivemos uma segunda perda, que foi a das ilusões. E foi Honoré de Balzac que nos disse como o homem moderno foi prematuramente perdendo as ilusões. A terceira perda foi a das ideologias. Alguns pensadores norte-americanos, como Daniel Beher e outros, mas sobretudo os desconstrucionistas franceses, trabalharam esse tema com mais fertilidade, com mais fecundidade.

A perda das ideologias é também a perda das certezas, porque a ideologia é a residência da certeza. Toda ideologia é portadora de certezas. E progressivamente fomos vendo que aquelas referências que nos protegiam tanto não tinham aquele caráter tão inabalável que nos diziam ter, ou que estavam prometidas para ter.

Finalmente, a perda do emprego. Essa perda se dá no momento que nós vivemos hoje. A perda do emprego pode ser pura e simplesmente, para certas camadas sociais, a ausência do vínculo contratual empregatício, ou pode ser pura e simplesmente o mau salário. Considero que os professores universitários no Brasil de hoje, ou no Brasil dos últimos dez anos, são semi-empregados, na medida em que dispõem de um salário que não corresponde às exigências técnicas do desempenho intelectual de um professor universitário.

A Modernicade é acronológica, filtra-se no Modernismo. E temos, finalmente, no após-guerra, o que eu chamo de contra-Modernidade. São aqueles que promoveram o retorno a formas fixas, aos temas abstratos, que em vez de aprofundar e levar adiante a experiência moderna, pelo contrário, sublimizaram, voltaram à estética pré-romântica, à estética do sublime, à estética das palavras bonitas, à má gestão da palavra, porque, na medida em que há uma delapidação de palavras, há, conseqüentemente, um gerenciamento ineficaz do poema. E o poema do após-guerra é um poema que, mais ou menos, nos deixa ver de uma maneira bem explícita essas diferentes formas de manifestações.

Há também aqueles que eu chamo "os adoráveis marginais", porque coincidem, cronologicamente, com essas figuras, mas não estão dentro do sistema. 
Guimarães Rosa mesmo pode ser considerado um marginal. Ele estréia bem depois e vai tendo progressivo e difícil reconhecimento, até a posição de hoje. O mesmo se pode dizer de Clarice Lispector, que até hoje não foi entendida. Eu me lembro de alguém se queixar muito das interpretações estruturalistas que levantavam as isotomias e uma série de palavras complicadas, faziam levantamentos quase estatísticos, e chegavam a conclusões que não diziam o lado verdadeiro da Clarice, o lado escondido da Clarice, o lado sombra da Clarice. O forte de Clarice Lispector não é o sol, é a sombra, ou a capacidade de transformar a sombra em sol. Isso é Clarice Lispector e, evidentemente, não se enquadra nessas figuras que estão aí.

Temos ainda nesse quadro João Cabral de Melo Neto, que é também uma figura atípica, que não pertence especificamente a nenhuma geração. Sua estréia foi em 1942, com o livro A pedra do sono, e ninguém tomou conhecimento dele, até 1954, quando ele ganhou o Prêmio de Poesia do IV Centenário de São Paulo com o livro O Rio. Podemos colocar também nesse nível dos "adoráveis marginais" Rubem Fonseca, Dalton Trevisan, e alguns outros.

A crítica literária, evidentemente, era uma atividade ligada ao jornal. Estava ali cotidianamente num rodapé de jornal. Havia inclusive essa intenção de paginação. Quando comecei a fazer uma crítica no Correio da Manbã, Santiago Dantas comprou o Jornal do Commercio, prometendo um grande acontecimento intelectual, e me convidou para ser o crítico. Ali havia uma introdução em que ele dizia: "Esse rodapé pertenceu a Sílvio Romero, Medeiros e Albuquerque, José Veríssimo" etc. Então, havia uma crítica de rodapé que tinha um prestígio enorme. Essa crítica militante foi progressivamente desaparecendo porque a estrutura empresarial do jornal reprogramou o seu espaço, econômica e financeiramente, e, conseqüentemente, aquele espaço passou a ser um espaço ocioso, porque hoje no Brasil seria impossível uma crítica semanal para dar conta do movimento editorial brasileiro. Com o que se publica hoje no Brasil um crítico semanal estaria fadado a cometer omissões graves.

Essa crítica de jornal foi transitando, progressivamente, para a Universidade. Inicialmente em um debate que opôs Impressionismo e Nova Crítica. Os protagonistas desse debate são Álvaro Lins e Afrânio Coutinho. Eu pessoalmente às vezes sou identificado com a Nova Crítica, mas não tive nada a ver com a Nova Crítica, até porque não tenho nada a ver com a glória da Nova Crítica, porque terminou predominando um tipo de mentalidade reflexiva que não estava presente na crítica impressionista, mas eu não contribuí.

Quando cheguei, já havia uma guerra terminada, e os novos padrões de compreensão crítica se impuseram ao velho impressionismo, mesmo que talentoso. Distingo muito os impressionistas talentosos, aqueles que são capazes de falar de dentro da obra. Para mim, um modelo de impressionista que me toca muito, que me sensibiliza enormemente, é Roberto Alvim Corrêa. Esse era capaz de entrar na intimidade da alma humana, entrando na intimidade do texto literário. 
Não pertenci a esse debate. E acho que houve uma tradição, não muito dolorosa, uma espécie de upgrade da crítica impressionista para a universitária. Nesta tensão alguns críticos foram capazes de sobreviver com muita dignidade. O primeiro deles é Antonio Candido, que chegou a fazer uma crítica militante e publicou um volume chamado Brigada ligeira, onde está essa crítica espontânea, essa detonação em cima do aparecimento do livro.

Num volume de ação menor, porque não chegaram a ser crítico semanal debruçado sobre o movimento editorial, temos Alfredo Bosi, Roberto Schwarz, Antonio Carlos Secchin, que é também alguém que aparece nas colunas de jornais, e com igual e semelhante vivacidade desempenha a sua tarefa universitária. Ivan Junqueira, também crítico, parece-me que não ensinou na Universidade, mas nos ensina todo dia mesmo fora da Universidade. Este é um caso raro - não costumo abrir concessões para poetas que fazem crítica. Acho que os poetas que fazem crítica, primeiro, estão desaparelhados tecnicamente e, segundo, fazem a crítica da poesia deles, fazem projeções da poesia deles, discordam do que é diferente deles. Então, o poeta crítico é vesgo. Os poetas não costumam ser capazes de aprofundar a leitura de poemas alheios, porque não estão instrumentalizados. Mas existem exceções raríssimas, e o nosso Ivan Junqueira é uma nesse manancial interminável de poetas candidatos a crítico. Os críticos são mais humildes, não são candidatos a poeta.

Como sou da teoria de que a poesia não é propriedade privada do poema, sou capaz de ver em alguns críticos, como Ortega y Gasset, que foi meu professor, Gilberto Freyre, Roland Barthes, sou capaz de ver nesses ensaístas uma poesia que às vezes não encontro nos poetas profissionais, naqueles que são fazedores de versos.

Este é o meu quadro, impreciso, é um pouco o meu percurso, o meu diálogo com as pessoas, onde sempre fui um coadjuvante, jamais um protagonista. E é assim que vou levando, conduzindo o meu trabalho intelectual. Hoje sou apenas um ensaísta, não faço avaliações, não cometo a temeridade dos julgamentos imediatos. Sou apenas o cultor de uma forma incerta, que é o ensaio, e também um professor que ensina para aprender.

RESUMO - ESTE ARTIGO descreve o percurso da crítica literária no Brasil e suas conexões com outros países como França, Espanha, Estados Unidos, Alemanha.

PALAVRAS-CHAVE: Reflexão, Dialética, Hermenêutica, História, Julgamento.

ABSTRACT - THIS ESSAY describes the evolution of literary criticism in Brazil and how it relates to that of other countries - including France, Spain, United States and Germany.

KEr-WORDS: Reflection, Dialectics, Hermeneutics, History, Judgment.

Eduardo Portella, ensaísta, é professor emérito da Universidade Federal do Rio de Janeiro e membro da Academia Brasileira de Letras. @ - portell@uol.com.br

Recebido em 19.9.05 e aceito em 22.9.05. 